\title{
Review: Endoplasmic Reticulum-Associated Degradation (ERAD)- Dependent Control of (Tri)terpenoid Metabolism in Plants
}

Authors

Marie-Laure Erffelinck ${ }^{1,2}$, Alain Goossens ${ }^{1,2}$

Affiliations

1 Ghent University, Department of Plant Biotechnology and Bioinformatics, Ghent, Belgium

2 VIB Center for Plant Systems Biology, Ghent, Belgium

Key words

3-hydroxy-3-methylglutaryl-coenzyme A reductase, mevalonate, triterpenoid, endoplasmic reticulum associated degradation, endoplasmic reticulum stress, saponin

received January 31,2018

revised May 17, 2018

accepted May 23, 2018

Bibliography

DOI https://doi.org/10.1055/a-0635-8369

Published online June 15, 2018 | Planta Med 2018; 84: 874-

880 @ Georg Thieme Verlag KG Stuttgart · New York I

ISSN 0032-0943

Correspondence

Prof. Dr. Alain Goossens

VIB Center for Plant Systems Biology, Ghent University,

Department of Plant Biotechnology

Technologiepark 927, B-9052 Ghent, Belgium

Phone: + 3293313851 , Fax: + 3293313809

alain.goossens@psb.vib-ugent.be

\section{ABSTRACT}

Plants are sessile organisms. Therefore, they developed the capacity to quickly respond to biotic and abiotic environmental stresses, for instance by producing a broad spectrum of bioactive specialized metabolites. In this defense response, the jasmonate phytohormones can instigate a signaling cascade that leads to the specific elicitation and reprograming of numerous metabolic pathways. Recent research progress has provided several insights into the regulatory networks of many specialized metabolic pathways, mainly at the transcriptional level. Nonetheless, our view on the regulation of defense metabolism remains far from comprehensive. Here, we describe the recent advances obtained with regard to one aspect of the regulation of plant specialized metabolism, namely the posttranslational regulation of enzyme stability. We focus on terpenoid biosynthesis and in particular on the rate-limiting and well-investigated enzyme of the terpenoid precursor pathway, 3-hydroxy-3-methylglutaryl-coenzyme A reductase (HMGR). There are clear similarities, as well as important mechanistic differences, among the components involved in the posttranslational regulation of terpenoid biosynthesis via HMGR in plants, yeasts, and mammals. Furthermore, in plants, several of these components evolved to respond to specific signaling cues. Indeed, the elements of the plant endoplasmic reticulum-associated degradation (ERAD) and ER stress-associated processes can be induced upon environmental stresses and during specific developmental processes, thereby allowing a unique posttranslational regulation of terpenoid biosynthesis pathways.

\section{Introduction}

Plants are stationary by nature. Consequently, they are constantly challenged, often coping with biotic and abiotic stresses. Therefore, metabolic plasticity is crucial for their survival. A good example of this flexibility is the production of a myriad of bioactive specialized metabolites such as terpenoids, alkaloids, and phenolic compounds [1]. This review focuses on the terpenoids (also known as isoprenoids), which belong to a functionally and structurally diverse class of molecules with tens of thousands of different identified members in existing plant species and can be either widespread or restricted to a specific species or taxa. Numerous terpenoids can be considered essential, because they play a cru- cial role in environmental adaptation, plant defense, and plant-environment interaction. For instance, they can serve as attractants for pollinators or seed-dispersing animals and repellents for herbivores or pathogens [2].

Terpenoids such as phytosterols, carotenoid pigments, electron transport chain components (quinones), and signaling molecules including gibberellins, ABA, BR, cytokinins, strigolactones, and phytoecdysteroids are associated with primary metabolism, regulating plant growth and development, photosynthesis, membrane permeability, and fluidity and are therefore occurring in all plant species [3-8].

Economically, many specialized terpenoids have beneficial properties for humans and are currently used for clinical purposes 


\begin{tabular}{|c|c|}
\hline \multicolumn{2}{|c|}{ ABBREVIATIONS } \\
\hline $\mathrm{ABA}$ & abscisic acid \\
\hline bHLH & basic helix-loop-helix \\
\hline BiPs & binding proteins \\
\hline BIS & basic helix-loop-helix (bHLH) iridoid synthesis \\
\hline BR & brassinosteroids \\
\hline bZIP & basic leucine-zipper \\
\hline DMAPP & dimethylallyl pyrophosphate \\
\hline Doa10 & degradation of alpha 10 \\
\hline DRY2 & drought hypersensitive 2 \\
\hline ER & endoplasmic reticulum \\
\hline ERAD & endoplasmic reticulum-associated degradation \\
\hline ERQC & ER protein quality control \\
\hline FPP & farnesyl pyrophosphate \\
\hline GGOH & geranylgeraniol \\
\hline GGPP & geranylgeranyl pyrophosphate \\
\hline gp78 & glycoprotein 78 \\
\hline HMGR & $\begin{array}{l}\text { 3-hydroxy-3-methylglutaryl-coenzyme A } \\
\text { reductase }\end{array}$ \\
\hline HMG-CoA & HMG-coenzyme A \\
\hline HR & hypersensitive response \\
\hline HRD & HMGR degradation \\
\hline IPP & isopentenyl pyrophosphate \\
\hline IRE1 & inositol-requiring protein 1 \\
\hline JA & jasmonic acid or jasmonate \\
\hline lew1 & leaf wilting 1 \\
\hline MEP & 2-C-methyl-D-erythritol 4-phosphate \\
\hline МКВ1 & makibishi 1 \\
\hline MVA & mevalonic acid or mevalonate \\
\hline MYC & bHLH transcription factor \\
\hline NAC & $\begin{array}{l}\text { no apical meristem (NAM), Arabidopsis thaliana } \\
\text { activating factor } 1 \text { and } 2 \text { (ATAF1 and }-2 \text { ), and } \\
\text { cup-shaped cotyledon (CUC2) }\end{array}$ \\
\hline OSER & organized smooth ER \\
\hline P450 & cytochrome P450s \\
\hline RING & really interesting new gene \\
\hline SA & salicylic acid \\
\hline SAR & systemic acquired resistance \\
\hline SSD & sterol-sensing domain \\
\hline SQE & squalene monooxygenase \\
\hline SUD1 & suppressor of DRY2 effects 1 \\
\hline TSAR & $\begin{array}{l}\text { triterpene saponin biosynthesis activating } \\
\text { regulator }\end{array}$ \\
\hline UbiA & polyubiquitin \\
\hline UBIAD1 & $\begin{array}{l}\text { UbiA prenyltransferase domain-containing } \\
\text { protein-1 }\end{array}$ \\
\hline UDP & uridine diphosphate \\
\hline UPR & unfolded protein response \\
\hline
\end{tabular}

[9-14]. Among these terpenoids are the anticancer agent paclitaxel (taxol), which is a naturally occurring diterpenoid produced by Taxus brevifolia Nutt. (Coniferae) and T. baccata L. (Coniferae) and the antimalarial agent artemisinin, a sesquiterpenoid lactone from Artemisia annua L. (Asteraceae) [15-17]. The nonfood indus- try uses latex, extracted from Hevea brasiliensis Müll.Arg. (Euphorbiaceae) or the rubber tree, the main source of natural rubber for the production of tiers, tubing, elastics, and toys [18]. Another highly valued terpenoid in the flavor industry is the diterpenoid menthol produced by Mentha x piperita L. (Lamiaceae) [19,20].

Despite their structural variability, all terpenoids are composed of a set amount of five-carbon $\left(C_{5}\right)$ isoprene (2-methyl-1,3-butadiene) units, corresponding to their classes [21]. The biochemically active forms of isoprene are IPP and its allylic isomer DMAPP, both biosynthesized by two compartmentalized core pathways [22], the MVA pathway that operates in the cytosol, the ER and peroxisomes, and the MEP pathway that takes place in the plastids [23-29]. Plants uniquely harbor both pathways, although there is a set allocation of the two pathways among the different kingdoms of life [30]. In essence, in higher plants, the MVA pathway is responsible for the biosynthesis of the sesqui- and triterpenoids $\left(C_{15}, C_{30}\right)$ and the MEP pathway for the formation of mono-, di-, some sesquiterpenoids $\left(C_{10}, C_{20}, C_{15}\right)$, and plastoquinones [31].

To date, multiple studies have focused on the regulation of the core terpenoid biosynthesis reactions, in particular the rate-limiting ER-localized enzyme of the MVA pathway HMGR, mainly to decipher the control of the biosynthesis of specific end-products of the pathways [8]. This review will focus on posttranslational regulation of enzymes that are involved in terpenoid precursor biosynthesis as well as the pathway branches leading to the production of specialized metabolites and in particular the triterpenoids of which the biosynthetic enzymes are predominantly localized in the ER. Consequently, ER-centralized regulation of enzyme stability executed by ERAD machinery and its associated processes play an essential role in the regulation of these metabolic pathways.

\section{Biosynthesis of Triterpenoids at the ER Membrane}

The class of triterpenoids $\left(C_{30}\right)$ in plants comprises primary metabolites such as phytosterols and BR and the specialized metabolites called saponins that serve as defense compounds against pathogens and herbivores [10].

Triterpenoid saponin biosynthesis starts in the cytosol with the "head-to-tail" condensation of two IPP units with one DMAPP unit, generating FPP. All consecutive biosynthesis steps towards triterpenoid saponins take place at the ER membrane. Two FPPs fuse "head-to-head" to form linear squalene, catalyzed by squalene synthase. Squalene is subsequently epoxidized by squalene monooxygenase (SQE) to 2,3-oxidosqualene, the last common intermediate in saponin and sterol biosynthesis. 2,3-oxidosqualene is further cyclized by specific oxidosqualene cyclases to either cycloartenol, the plant sterol precursor, or other cyclization products that are further oxidized by one or more P450s to form a wide variety of specific triterpenoid backbones or sapogenins. Finally, these sapogenins are further decorated by covalent attachment of sugar moieties by UDP-dependent glycosyltransferases, thereby further increasing the structural diversity of this metabolite class [32,33]. For a complete overview of the triterpenoid biosynthesis in plants, we refer to Thimmappa et al. (2014) [34]. 
The amphipathic nature of triterpenoid saponins gives them economically valuable properties. For instance, saponin extracts from Quillaja saponaria Molina (Quillajaceae) have been used as emulsifiers and industrial soaps in the nonfood industry [35-39]. Furthermore, extracts of Glycyrrhiza glabra L. (Fabaceae) and Panax ginseng Baill. (Araliaceae), which contain glycyrrhizin and ginsenoside saponins, respectively, are commonly used as herbal medicines [40-42]. Glycyrrhizin is also used as natural sweetener in the food industry [43].

\section{Transcriptional Regulation of Terpenoid Biosynthesis}

Biologically, biosynthesis of plant triterpenoid saponins is controlled by a signaling cascade wherein the oxylipin-derived JA phytohormone is the protagonist [44-46]. In the last years, much effort has been made to identify transcription factors that control the terpenoid biosynthesis upon JA perception. First, a bHLH transcription factor MYC2 has been shown to control the sesquiterpenoid biosynthesis in Arabidopsis thaliana L.Heynh (Brassicaceae), Solanum lycopersicum L. (Solanaceae), and A. annua [47-50]. Shortly thereafter, two MYC2-unrelated bHLH transcription factors were identified in Cucumis sativus L. (Cucurbitaceae) that regulate the production of cucurbacitins [51]. Furthermore, in Catharanthus roseus (L.) G. Don (Apocynaceae), two bHLH transcription factors, bHLH iridoid synthesis 1 and 2, have been shown to induce the monoterpenoid branch of the monoterpenoid indole alkaloid pathway [52].

Recently, mechanisms that specifically control triterpenoid biosynthesis have also been identified. For example, in Medicago truncatula Gaertn. (Fabaceae), bHLH transcription factors TSAR1 and TSAR2, homologs of BIS1 in C. roseus, and therefore also unrelated to MYC2, were found to boost the nonhemolytic and hemolytic triterpenoid saponin biosynthesis, respectively $[53,54]$. BIS and TSAR homologs also control the production of antinutritional triterpenoid saponins in quinoa seeds and soyasaponins in Glycyrrhiza uralensis Fisch. Ex DC. (Fabaceae) [55, 56].

\section{Posttranslational Regulation of Enzyme Stability of the Terpenoid Biosynthetic Pathways in Plants}

Substantial effort has been made to identify regulatory enzymes of the IPP precursor pathways and their mode of action $[8,57$, 58]. One particular enzyme, HMGR, received much attention and is therefore the best-characterized enzyme of the MVA pathway in plants, yeasts, and mammals until now [59]. Because terpenoids are produced by all free-living organisms, it is not surprising that some regulatory and structural features of HMGR in the MVA pathway have been conserved and might have undergone parallel and functional evolution to cope with certain situations or suit specific requirements of organisms [60].

The mammalian genome and that of the fission yeast Schizosaccharomyces pombe contain only one gene encoding
HMGR, whereas the genome of the budding yeast Saccharomyces cerevisiae harbors two isozymes, and in all plant species studied so far, HMGR is encoded by a multigene family [26, 61-66].

All eukaryotic HMGRs are targeted to the ER and consist of an $\mathrm{N}$-terminal membrane domain with low sequence similarity, a Cterminal catalytic domain that is highly conserved and localized at the cytosolic site of the ER membrane, and a nonconserved flexible linker connecting the two [67]. Plant and mammalian HMGR is tetrameric, as a result of the oligomerization potential of the catalytic domain $[68,69]$. Roitelman et al. (1992) predicted that the membrane domain of mammalian HMGR contains eight transmembrane sequences, contrasting with the model of Chin et al. (1982), wherein HMGR spans the membrane seven times. A similar eight membrane-span model was predicted for yeast HMGR $[67,70,71]$. In plants, HMGR only contains two transmembrane domains $[26,61,72]$ ( $\triangleright$ Fig. 1 A-C). The mechanisms by which yeast and mammalian HMGR are regulated at multiple levels are profoundly described in a review by John S. Burg [73]. In this review, we will elaborate on the posttranslational control of HMGR activity by degradation.

The membrane domain of HMGR in mammals and HMG2 in S. cerevisiae is necessary for accelerated sterol or nonsterol (endproducts of the MVA pathway) feedback regulation by ERAD using the same machinery that is responsible for the elimination of improperly folded secretory proteins by proteasomal degradation $[71,74,75]$. Both HMGR in mammals and HMG2 in S. cerevisiae contain a SSD in the $\mathrm{N}$-terminal membrane domain, consisting of five consecutive transmembrane spans $[76,77]$. In mammals, it is this SSD that binds to Insig-1, an ER-retention protein, resulting in accelerated HRD by the gp78 machinery triggered by 24,25-dihydrolanosterol or oxysterol [78-81]. Furthermore, the nonsterol isoprenoid GGOH may act as an enhancer of degradation of mammalian HMGR by promoting the extraction of the ubiquitinylated HMGR from the ER, thereby facilitating degradation by the proteasome [82].

Likewise, two lipid signals control the rate of HMG2P turnover through ERAD, using the HRD machinery in S. cerevisiae [70,83]. GGPP may act by altering the conformation of the membrane domain of HMG2P and thereby inducing Insig-independent HRDmediated degradation of its incorrectly folded version and thus maintaining the lipid homeostasis in the cell [84]. An oxysterolderived signal can further enhance the MVA-derived signal-induced degradation ( $\bullet$ Fig. 1 A, B) [85]. A similar signal controlling the degradation of HMG1 in $S$. pombe remains to be discovered.

Furthermore, the ERAD E3 ubiquitin ligase Doa10 and TEB4 machinery in yeasts and mammals, respectively, are responsible for the sterol-dependent degradation of SQE to prevent accumulation of toxic sterol intermediates [86]. In plants, an analogous mechanism to target SQE has not been discovered yet.

Recently, it was discovered in mammals that sterols stimulate binding of UBIAD1, which uses GGPP to synthesize vitamin $K_{2}$, to a subset of HMGR, thereby inhibiting ERAD [87]. GGPP can trigger the release of UBIAD1 from HMGR, thereby enabling ERAD. This UBIAD1-dependent HMGR control system allows sterol-replete cells to synthetize MVA for the replenishment of GGPP [88].

That HMGR is also modulated at all levels in plants is reflected by the lack of correlation between enzyme activity, mRNA levels, 


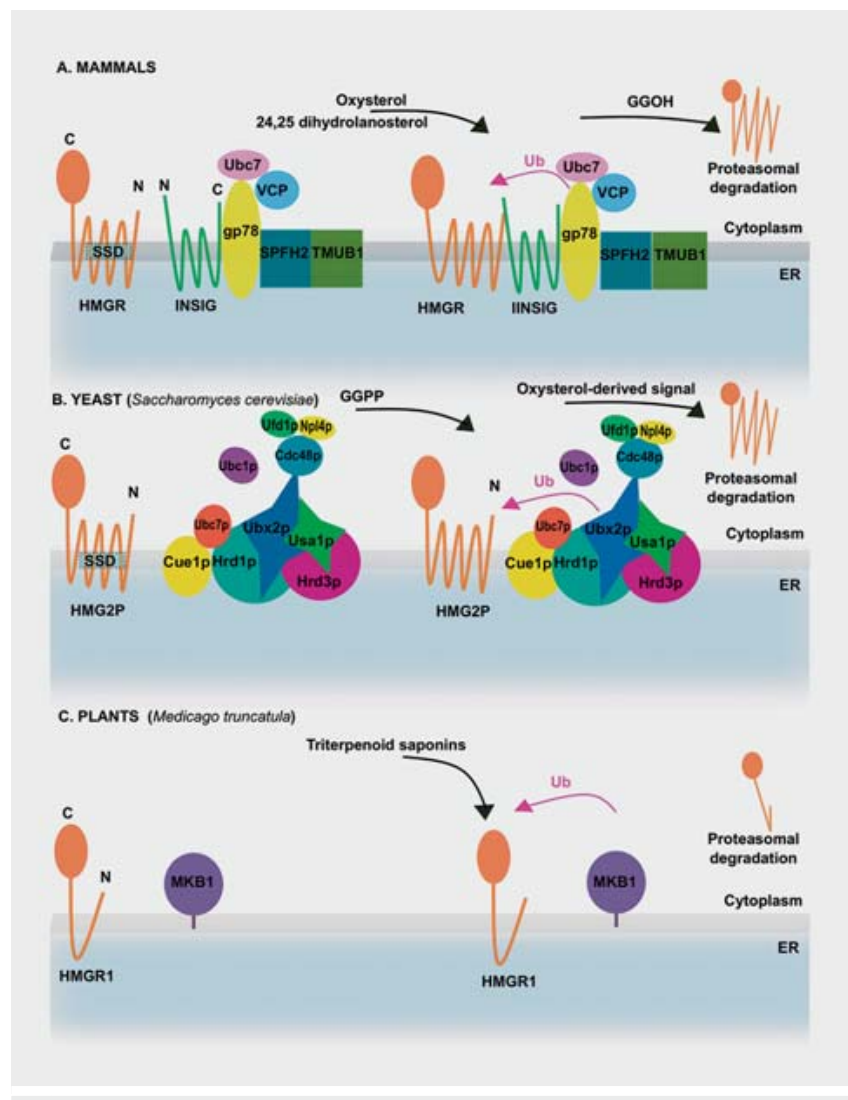

- Fig. 1 Regulated degradation of HMGR in mammals (A), yeasts (S. cerevisiae) (B), and plants ( $M$. truncatula) (C). A In the absence of sterols, HMGR does not bind Insig. In the presence of 24,25-dihydrolanosterol or oxysterols, Insig promotes ubiquitinylation (Ub) and proteasomal-dependent degradation of HMGR through sequential interactions with the $\mathrm{E} 2$ ubiquitin-conjugating enzyme Ubc7, the E3 ubiquitin ligase gp78, the ATPase VCP/p97, the SPFH domain-containing protein member 2 (SPFH2), and transmembrane and ubiquitin-like domain-containing protein 1 (TMUB1). $\mathrm{GGOH}$ possibly enhances the mammalian HRD by a mechanism downstream of ubiquitinylation. B GGPP induces a conformational change of HMG2P, thereby promoting recognition and ubiquitinylation by the HRD complex. HRDP3P is responsible for substrate recognition and delivery. HRD1P employs two E2 ubiquitin-conjugating enzymes: the primary soluble Ubc7p and Ubc1p. Ubc7p interacts with the membrane through the integral membrane protein Cue1p. Usa1p functions in the self-regulation of HRD1P. Ubx2p is responsible for the recruitment of the Cdc48p/Npl4p/Ufd1p ATPase complex, thereby catalyzing retrotranslocation of luminal and membrane-bound HRD substrates. An oxysterol-derived signal can also regulate HMG2P activity. $C$ Coinciding with high triterpenoid saponin levels, HMGR is recruited to the MKB1 E3 ubiquitin ligase complex for ubiquitinylation and subsequent proteasomal-dependent degradation in M. truncatula.

and protein content [26,89-92]. At the posttranslational level, plant HMGR activity can be controlled through noncovalent interactions with metabolic intermediates such as sterols, saponins, $A B A$, ubiquinone, and 4-hydroxybenzoic acid, but their mode of action awaits discovery [93]. Also, covalent modifications such as phosphorylation, glycosylation, and ubiquitinylation followed by proteasomal degradation can control HMGR activity [94-100].
Several observations support that an analogous type of proteasomal-dependent degradative control of HMGR in mammals and yeasts is also exerted in plants following diverse developmental and environmental cues, but the mode of action is still limitedly understood, even for a well-investigated enzyme such as HMGR. For example, in pea, HMGR activity declines rapidly when etiolated seedlings are irradiated with red light, which suggests that phytochrome-mediated signaling indirectly controls HMGR activity through a posttranslational mechanism [93]. Also, the linker region between the membrane domain and the catalytic domain of plant HMGR is rich in so-called PEST (Pro, Glu [and Asp], Ser, Thr) amino acids, which have been shown to be responsible for the turnover of ER-located proteins possibly by proteasomal degradation [101]. Contrarily, the membrane domain of plant HMGR is fairly small compared to HMGR in yeasts and mammals and does not contain a SSD, and plants do not express an ortholog of the ER-resident Insig-1 protein [61].

Nevertheless, in M. truncatula, a system that monitors the accumulation of bioactive triterpenoid saponins to secure plant development and integrity by turnover of HMGR was recently characterized. In particular, MKB1, a RING membrane-anchor E3 ubiquitin ligase without sequence homology to the yeast HRD and mammalian gp78 E3 ligases, was found to act as a posttranslational regulator of HMGR [102]. MKB1 recruits the ERAD system to regulate HMGR activity by controlling protein stability and hence the amount of saponin precursors generated via the MVA pathway ( $\triangleright$ Fig. 1 C). Therefore, silencing of MKB1 leads to an uncontrolled accumulation of monoglycosylated saponins and an aberrant root morphology.

Contrarily, SUD1, which is homologous in sequence and structure to the yeast Doa10 and human TEB4, was characterized as a positive posttranslational regulator of HMGR activity in $A$. thaliana [103]. In yeasts and mammals, the HDR and gp78 machinery, respectively, regulate HMGR activity by controlling protein stability, whereas SUD1 controls HMGR activity without changing the protein content but possibly by degrading a negative regulator of HMGR.

Besides clear similarities, there are also important mechanistic differences among the components involved in the terpenoid regulation through HMGR in plants, yeasts, and mammals. The nonconserved regions of plant HMGR may have steered the evolution of a specific control mechanism for HMGR activity, possibly regulated by specific saponins, their intermediates or plant-specific mediator proteins, since plants do not encode Insigs or Insig-like homologs. Identification of such mediators will be important for the understanding of this plant-specific degradative HMGR activity control mechanism. MKB1 possibly also targets other proteins than HMGR, such as P450s, SQE, chaperones, or regulators to protect itself against its own defense strategies.

In mammals for example, the ER-anchored hepatic P450s metabolize endo- and xenobiotics. Such agents can positively control liver P450 protein levels by increased synthesis or negatively via inactivation or degradation. Recently, an ERAD-dependent control mechanism using gp78 and C-terminus of Hsc70-interacting protein to target CYP3A4, the major human liver/intestinal P450, and the fast-turnover liver CYP2E1 for degradation, has been de- 
scribed [104]. Likewise, it is possible that also in plants such regulators exist that target ER-located proteins such as P450s.

The membrane domain of plant, mammalian, and yeast HMGR is not only a determinant of its own turnover; it is also responsible for the morphology of its residency, the ER. The ER is a dynamic net of tubules, sheets and cisternae harboring terpenoid biosynthetic enzymes and the machinery controlling them. The constellation of the ER net and its tenants may vary, depending on the cellular demands. For example, gland cells in plants require an increased ER net to accommodate the production of terpenoids [105]. Likewise, the biosynthesis of steroid hormones requires an expanded ER in mammalian adrenocortical cells [106].

This ER expansion, also called ER hypertrophy, was first discovered in compactin (competitive inhibitor of reductase)-resistant Chinese hamster ovary UT-1 cells that were obtained by stepwise adaptation to grow at an increased concentration of compactin [107]. These cells generated crystalloid ER membranes consisting of hexagonal or cubical tubules/sheets [107-110].

Also, in S. cerevisiae a similar phenomenon was described. Overexpression of HMG1P resulted in the proliferation of karmellae, which are stacked cisternae on the outer nuclear envelope, whereas overexpression of HMG2P leads to the formation of peripheral ER membrane stacks and short karmellae [69, 111, 112]. All of these structures are categorized as OSER [113]. Although the mechanisms and signals that trigger this ER proliferation are to date still unknown, the membrane-spanning domains six and seven in yeast and mammal HMGR determine the ER morphogenesis potential, thereby regulating the catalytic activity of the Cterminal domain [112]. Nevertheless, a properly folded catalytic domain is indispensable to induce OSER biogenesis [69]. A. thaliana encodes three HMGR isoforms. HMG1 encodes HMGR1S and HMGR1L, the latter which holds a 50-amino acid residue extension at the N-terminus, whereas HMG2 encodes HMGR2. Expression of the membrane domain of HMGR1S and HMG2 leads to the reversible proliferation and morphogenesis of the ER in every cell type of diverse plant species [114]. Apparently, an Nterminal Arg-motif does not only serve as an ER-retention signal but it is also a requisite to trigger the biogenesis of OSER in plants [114].

\section{The Regulatory Role of ERAD and Associated Processes and Signals that Activate or Modulate Them in Plants}

Nearly one-third of the newly synthesized proteins allocated to the secretory pathway in the ER are misfolded. Therefore, a highly efficient ERQC mechanism is responsible to secure correct folding and removal by ERAD in case the proteins do not meet the conformational standard [115-119]. This process consists of four steps, namely recognition by E3 ubiquitin ligases embedded in the ER, ubiquitinylation, dislocation from the ER, and ultimately degradation of the ubiquitinylated folding-defective proteins by the $26 \mathrm{~S}$ proteasome in the cytosol [116].

Adverse environmental conditions or certain developmental stages can trigger the accumulation of unfolded and misfolded proteins in the ER [120]. This imposed ER stress may elicit a conserved UPR, which consists of specific transcriptional and translational regulatory cascades that bring the ER folding capacity in line with demands by for example reducing the synthesis of secreted or membrane proteins or by increasing folding-assisting proteins such as chaperones and foldases or other components of the ERQC system.

ERQC, ERAD, or UPR deficiencies in plants can lead to an increased sensitivity to environmental stresses or an inadequate development. In the following sections, we will discuss the hitherto studied players in plant ERAD and ER stress-associated processes, their link to terpenoid biosynthesis regulation, and their involvement towards biotic and abiotic stresses and development.

\section{ER Stress Response and Biotic Stress}

Biotic stress triggers signaling molecules such as the plant hormones SA and JA to elicit a downstream defense response [121]. For instance, SA activates resistance against biotrophic pathogens by inducing a HR and SAR [122], whereas JAs activate a defense response against herbivorous insects and necrotrophic pathogens by the production of anti-insect proteins [123] and vegetative storage proteins [124] or specialized metabolites such as terpenoids, polyamines, quinones, alkaloids, phenylpropanoids, and glucosinolates $[44,45]$. Depending on the situation, the interdependent SA- and JA-signaling pathways can work synergistically or antagonistically through modulation by other hormones [125-127].

Plants harbor several ER-localized stress sensors and transducers such as the bZIP transcription factors bZIP28, bZIP17, and bZIP60, the NAC transcription factors NAC062 and NAC089, and the RNA-splicing enzyme IRE1. Upon pathogen infection, IRE1 is activated by a still unknown mechanism, thereby enabling splicing of bZIP60 mRNA, resulting in the translation of an active form of bZIP60 that translocates to the nucleus, where it induces an ER stress response ( $\triangleright$ Fig. 2 ). The IRE1a mutant in A. thaliana, which is deficient in bZIP60 mRNA splicing, is more sensitive to pathogen infection and is defective in establishing SAR [128]. Likewise, in Nicotiana benthamiana Domin. (Solanaceae), silencing of bZIP60 resulted in plants that are more susceptible to Pseudomonas cichorii infection [129].

The link between the SAR and secretory pathway was further reinforced by the observation that an $A$. thaliana mutant in BiP2, encoding a highly abundant ER-luminal heat shock protein 70 chaperone, was impaired in the induction of the SA-responsive gene $P R 1$ [130]. It is possible that upon biotrophic pathogen-induced stress, the UPR is steering a SA response, thereby antagonizing a JA-response and thus also the production of specialized metabolites, including terpenoids.

\section{ER Stress Response and Abiotic Stress}

BiPs can also play a role in abiotic stress responses. Overexpressing BiPs in soybean or tobacco confers drought tolerance, possibly as the result of a dynamic interplay between drought stress responses and UPR $[131,132]$. For example, a lew 1 mutant in $A$. thaliana, encoding a cis-prenyltransferase for the synthesis of dolichols, which are long-chain unsaturated polyterpenoids, showed a leaf-wilting phenotype under normal growth conditions [133]. 


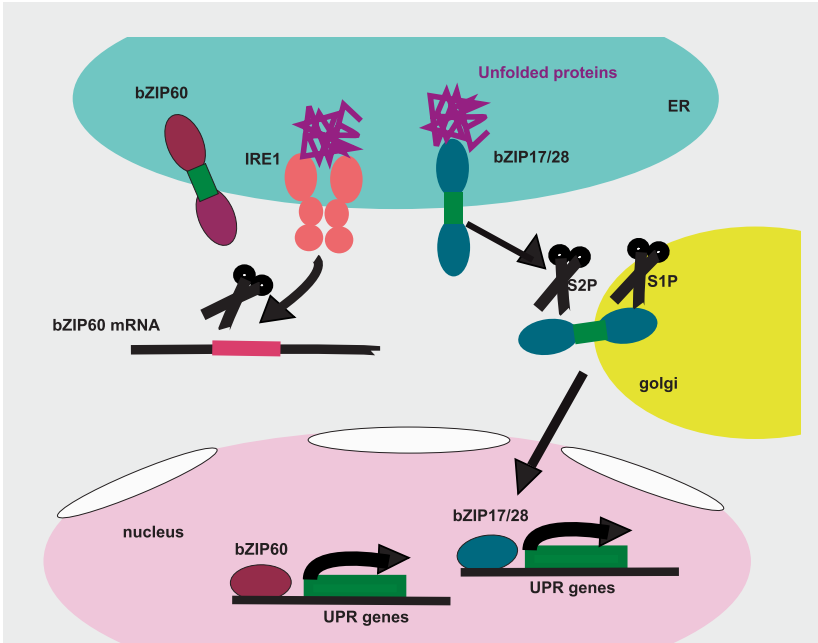

- Fig. 2 A stylistic representation of the UPR in plants. When activated, by a still unknown mechanism, plant IRE1 splices out a 23base intron of bZIP60 mRNA, inducing in a frame shift that results in the elimination of the transmembrane domain of the bZIP60p and thereby targeting active bZIP60 to the nucleus to induce expression of UPR genes. In a second mechanism, upon salt or heat stress, bZIP17/28 relocates to the nucleus through the Golgi where it is sequentially cleaved by the transcription factor peptidases, Site-2proteases 1 and 2 , to induce the transcription of several UPR genes.

Dolichols promote protein trafficking in the ER by carrying sugars for protein glycosylation. Consequently, a mutation in lew1 can cause a loss of membrane integrity and reduced protein glycosylation. Drought stress resulted in higher expression of the UPR genes BiP and bZIP60 and earlier expression of the abiotic stressresponsive genes Cold Regulated 47 and Cold Regulated $29 A$ in the lew1 mutant. This implicates that lew1 links the MVA-dependent dolichol biosynthesis, the UPR pathway, and the abiotic stress response in Arabidopsis.

Furthermore, it has been shown in A. thaliana that the UPR can also be involved in the high salt or heat stress response. Upon heat stress, bZIP28 relocates from the ER to the nucleus through the Golgi, where it is cleaved and activated by the sequential action of the peptidases Site-2-protease 1 and 2 [134, 135]. A similar activation mechanism is triggered for bZIP17 upon salt stress ( $\triangleright$ Fig. 2) [136]. Mutating A. thaliana S2P impaired proteolytic activation and nuclear relocation of bZIP17 and bZIP28 [137].

Recently, a link was found between ER stress signaling, stress acclimatization, and BRs, which are terpenoid signaling molecules involved in growth and development. Abiotic stress can disable maturation and translocation of brassinosteroid insensitive 1 , a leucine-rich repeat receptor kinase, from the endomembrane to the plasmamembrane, implicating that S2P-activated bZIPs can steer brassinosteroid insensitive 1 delivery to the plasma membrane and directly regulate BR signaling required for stress acclimatization and growth [137].

\section{ER Stress Response and Plant Development}

Deficiencies in the ERQC, ERAD, or UPR machinery can cause slower growth and sometimes even sterility. For example, $A$. thaliana S2P can control root development through BR signaling [137]. Furthermore, A. thaliana S2P monitors bZIP17 activation and therefore controls the expression of negative regulators of $\mathrm{ABA}$ signaling, enabling S2P to desensitize $\mathrm{ABA}$ signaling during seed germination [138]. Furthermore, a short root phenotype was observed in double ire1a ire1b mutants, suggesting that the UPR machinery can influence root development in normal conditions $[139,140]$.

\section{Concluding Remarks and Perspectives}

The past few years have yielded remarkable progress in our understanding of the molecular details underlying the posttranslational regulation of terpenoid biosynthesis through modulation of enzyme stability. However, the acquired insights are mostly limited to HMGR, the rate-limiting enzyme of the MVA-dependent IPP precursor pathway. Although there are important mechanistic differences across eukaryotic species in the regulatory control of this extremely conserved protein, there are also clear similarities. The signals that trigger each mode of regulation, although different in their exact identity, may be considered analogous in mammals, yeasts, and plants. Regulated degradation of HMGR seems indeed associated with a lipid signal: 24,25-dihydrolanosterol and an oxysterol in mammals, GGPP and oxysterols in yeasts and a yet unknown terpenoid intermediate in plants. The mechanistic differences may be caused by the divergent regions of HMGR in eukaryotes. As such, evolution may have allowed plants to develop multiple and plant-specific control mechanisms for HMGR activity and stability, possibly controlled by plant-specific triterpenoids, their intermediates, and/or by plant-specific protein mediators. For instance, orthologs of the HMGR-binding Insigs or Insig-like chaperones, conserved between yeasts and mammals, are not present in plants. Furthermore, it is possible that additional regulators, such as plant-specific E3 ubiquitin ligases, are able to target other ERlocalized proteins than HMGR (e.g., triterpenoid biosynthesis enzymes such as SQE or P450s). This could be an ingenious system for plants to guarantee survival in a hostile environment while simultaneously ensuring protection against their own defense mechanism when being attacked. It will be of utmost importance to gain more knowledge about the posttranslational regulatory mechanism of the proteasome-dependent degradation of HMGR and the mechanisms that control the more downstream enzymes of the terpenoid biosynthesis pathway in plants. There are indications of involvement of ERAD and its associated processes such as the UPR in the regulation of terpenoid biosynthesis. Many members of the ERAD and associated mechanisms are responsive to environmental stresses and show engagement in certain developmental processes linked to terpenoid metabolism. Unraveling the links between the ERAD machinery, the ER stress response, and that of terpenoid metabolism can represent a major advance in the elucidation of plant hormonal and metabolic regulatory networks. 


\section{Acknowledgements}

We thank Jacob Pollier and Annick Bleys for help in preparing the manuscript. This work was supported by the Special Research Funds from Ghent University (project no. BOF01J14813).

Conflict of Interest

The authors declare no conflict of interest.

\section{References}

[1] Croteau R, Kutchan TM, Lewis NG. Natural Products (secondary Metabolites). In: Buchanan B, Gruissem W, Jones R, eds. Biochemistry \& molecular Biology of Plants. Rockville: American Society of Plant Physiologists; 2000: $1250-1318$

[2] Gershenzon J, Dudareva N. The function of terpene natural products in the natural world. Nat Chem Biol 2007; 3: 408-414

[3] Kuzuyama T, Seto H. Diversity of the biosynthesis of the isoprene units. Nat Prod Rep 2003; 20: 171-183

[4] Sacchettini JC, Poulter CD. Creating isoprenoid diversity. Science 1997; 277: $1788-1789$

[5] Bouvier F, Rahier A, Camara B. Biogenesis, molecular regulation and function of plant isoprenoids. Prog Lipid Res 2005; 44: 357-429

[6] Tarkowská D, Strnad M. Isoprenoid-derived plant signaling molecules: biosynthesis and biological importance. Planta 2018; 247: 1051-1066

[7] Bohlmann J, Keeling Cl. Terpenoid biomaterials. Plant J 2008; 54: 656669

[8] Vranová E, Coman D, Gruissem W. Structure and dynamics of the isoprenoid pathway network. Mol Plant 2012; 5: 318-333

[9] Netala VR, Ghosh SB, Bobbu P, Anitha D, Tartte V. Triterpenoid saponins: a review on biosynthesis, applications and mechanism of their action. Int J Pharm Pharm Sci 2015; 7: 24-28

[10] Moses T, Papadopoulou KK, Osbourn A. Metabolic and functional diversity of saponins, biosynthetic intermediates and semi-synthetic derivatives. Crit Rev Biochem Mol Biol 2014; 49: 439-462

[11] Chang MCY, Keasling JD. Production of isoprenoid pharmaceuticals by engineered microbes. Nat Chem Biol 2006; 2: 674-681

[12] Rohmer M, Grosdemange-Billiard C, Seemann M, Tritsch D. Isoprenoid biosynthesis as a novel target for antibacterial and antiparasitic drugs. Curr Opin Investig Drugs 2004; 5: 154-162

[13] Rohdich F, Bacher A, Eisenreich W. Isoprenoid biosynthetic pathways as anti-infective drug targets. Biochem Soc Trans 2005; 33: 785-791

[14] Pollier ], Goossens A. Oleanolic acid. Phytochemistry 2012; 77: 10-15

[15] Paddon C], Westfall PJ, Pitera D], Benjamin K, Fisher K, McPhee D, Leavell MD, Tai A, Main A, Eng D, Polichuk DR, Teoh KH, Reed DW, Treynor T, Lenihan J, Fleck M, Bajad S, Dang G, Dengrove D, Diola D, Dorin G, Ellens KW, Fickes S, Galazzo J, Gaucher SP, Geistlinger T, Henry R, Hepp M, Horning $T$, Iqbal $T$, Jiang $H$, Kizer L, Lieu B, Melis D, Moss N, Regentin R, Secrest S, Tsuruta H, Vazquez R, Westblade LF, Xu L, Yu M, Zhang Y, Zhao L, Lievense J, Covello PS, Keasling JD, Reiling KK, Renninger NS, Newman JD. High-level semi-synthetic production of the potent antimalarial artemisinin. Nature 2013; 496: 528-532

[16] Ro DK, Paradise EM, Quellet M, Fisher KJ, Newman KL, Ndungu JM, Ho KA, Eachus RA, Ham TS, Kirby J, Chang MCY, Withers ST, Shiba Y, Sarpong R, Keasling JD. Production of the antimalarial drug precursor artemisinic acid in engineered yeast. Nature 2006; 440: 940-943

[17] Jennewein S, Croteau R. Taxol: biosynthesis, molecular genetics, and biotechnological applications. Appl Microbiol Biotechnol 2001; 57: 1319

[18] van Beilen JB, Poirier Y. Establishment of new crops for the production of natural rubber. Trends Biotechnol 2007; 25: 522-529
[19] McCaskill D, Croteau R. Prospects for the bioengineering of isoprenoid biosynthesis. Adv Biochem Eng Biotechnol 1997; 55: 107-146

[20] Croteau R. Metabolism of monoterpenes in mint (Mentha) species. Planta Med 1991; 57: S10-S14

[21] Chen F, Tholl D, Bohlmann J, Pichersky E. The family of terpene synthases in plants: a mid-size family of genes for specialized metabolism that is highly diversified throughout the kingdom. Plant J 2011; 66: 212-229

[22] Lange BM, Rujan T, Martin W, Croteau R. Isoprenoid biosynthesis: the evolution of two ancient and distinct pathways across genomes. Proc Natl Acad Sci U S A 2000; 97: 13172-13177

[23] Carrie C, Murcha MW, Millar AH, Smith SM, Whelan J. Nine 3-ketoacylCoA thiolases (KATs) and acetoacetyl-CoA thiolases (ACATs) encoded by five genes in Arabidopsis thaliana are targeted either to peroxisomes or cytosol but not to mitochondria. Plant Mol Biol 2007; 63: 97-108

[24] Hemmerlin A, Hoeffler JF, Meyer O, Tritsch D, Kagan IA, GrosdemangeBilliard C, Rohmer M, Bach T]. Cross-talk between the cytosolic mevalonate and the plastidial methylerythritol phosphate pathways in tobacco Bright Yellow-2 cells. J Biol Chem 2003; 278: 26666-26676

[25] Dudareva N, Negre F, Nagegowda DA, Orlova I. Plant volatiles: recent advances and future perspectives. Crit Rev Plant Sci 2006; 25: 417-440

[26] Leivar P, González VM, Castel S, Trelease RN, López-Iglesias C, Arró M, Boronat $A$, Campos N, Ferrer A, Fernàndez-Busquets X. Subcellular localization of Arabidopsis 3-hydroxy-3-methylglutaryl-coenzyme A reductase. Plant Physiol 2005; 137: 57-69

[27] Merret R, Cirioni JR, Bach T], Hemmerlin A. A serine involved in actin-dependent subcellular localization of a stress-induced tobacco BY-2 hydroxymethylglutaryl-CoA reductase isoform. FEBS Lett 2007; 581: 5295-5299

[28] Simkin A], Guirimand G, Papon N, Courdavault V, Thabet I, Ginis O, Bouzid S, Giglioli-Guivarc'h N, Clastre M. Peroxisomal localisation of the final steps of the mevalonic acid pathway in planta. Planta 2011; 234: 903-914

[29] Eisenreich W, Bacher A, Arigoni D, Rohdich F. Biosynthesis of isoprenoids via the non-mevalonate pathway. Cell Mol Life Sci 2004; 61: 1401-1426

[30] Zhao L, Chang WC, Xiao Y, Liu HW, Liu P. Methylerythritol phosphate pathway of isoprenoid biosynthesis. Annu Rev Biochem 2013; 82: 497530

[31] Laule O, Fürholz A, Chang HS, Zhu T, Wang X, Heifetz PB, Gruissem W, Lange M. Crosstalk between cytosolic and plastidial pathways of isoprenoid biosynthesis in Arabidopsis thaliana. Proc Natl Acad Sci U S A 2003; 100: 6866-6871

[32] Osbourn A, Goss RJM, Field RA. The saponins - polar isoprenoids with important and diverse biological activities. Nat Prod Rep 2011; 28 : 1261-1268

[33] Augustin JM, Kuzina V, Andersen SB, Bak S. Molecular activities, biosynthesis and evolution of triterpenoid saponins. Phytochemistry 2011; 72: 435-457

[34] Thimmappa R, Geisler K, Louveau T, O’Maille P, Osbourn A. Triterpene biosynthesis in plants. Annu Rev Plant Biol 2014; 65: 225-257

[35] Cheeke PR. Actual and potential applications of Yucca Schidigera and Quillaja Saponaria Saponins in human and animal Nutrition. In: Oleszek W, Marston A, eds. Saponins in Food, Feedstuffs and medicinal Plants Proceedings of the phythochemical Society of Europe, vol. 45. Dordrecht: Springer; 2000: 241-254

[36] Guo S, Lennart K, Lundgren LN, Rönnberg B, Sundquist BG. Triterpenoid saponins from Quillaja saponaria. Phytochemistry 1998; 48: 175-180

[37] Zengín ACA. Potential application of Quillaja saponaria saponins as an antimicrobial soaking agent in leather industry. Journal of Textile \& Apparel/Tekstil ve Konfeksiyon 2013; 23: 55-61

[38] San Martín R, Briones R. Industrial uses and sustainable supply of Quillaja saponaria (Rosaceae) saponins. Econ Bot 1999; 53: 302-311

[39] Smułek W, Zdarta A, Pacholak A, Zgoła-Grześkowiak A, Marczak Ł, Jarzębski M, Kaczorek E. Saponaria officinalis L. extract: surface active 
properties and impact on environmental bacterial strains. Colloids Surf B Biointerfaces 2017; 150: 209-215

[40] Christensen LP. Ginsenosides: chemistry, biosynthesis, analysis, and potential health effects. Adv Food Nutr Res 2008; 55: 1-99

[41] Kim Y], Zhang D, Yang DC. Biosynthesis and biotechnological production of ginsenosides. Biotechnol Adv 2015; 33: 717-735

[42] Graebin CS, Verli H, Guimarães JA. Glycyrrhizin and glycyrrhetic acid: scaffolds to promising new pharmacologically active compounds. J Braz Chem Soc 2010; 21: 1595-1615

[43] Pandey DK, Ayangla NW. Biotechnological aspects of the production of natural sweetener glycyrrhizin from Glycyrrhiza sp. Phytochem Rev 2017; 17: $397-430$

[44] De Geyter N, Gholami A, Goormachtig S, Goossens A. Transcriptional machineries in jasmonate-elicited plant secondary metabolism. Trends Plant Sci 2012; 17: 349-359

[45] Pauwels L, Inzé D, Goossens A. Jasmonate-inducible gene: what does it mean? Trends Plant Sci 2009; 14: 87-91

[46] Zhou M, Memelink J. Jasmonate-responsive transcription factors regulating plant secondary metabolism. Biotechnol Adv 2016; 34: 441-449

[47] Goossens J, Mertens J, Goossens A. Role and functioning of bHLH transcription factors in jasmonate signalling. J Exp Bot 2017; 68: 1333-1347

[48] Kazan K, Manners JM. MYC2: the master in action. Mol Plant 2013; 6: 686-703

[49] Hong G], Xue XY, Mao YB, Wang L], Chen XY. Arabidopsis MYC2 interacts with DELLA proteins in regulating sesquiterpene synthase gene expression. Plant Cell 2012; 24: 2635-2648

[50] Spyropoulou EA, Haring MA, Schuurink RC. RNA sequencing on Solanum lycopersicum trichomes identifies transcription factors that activate terpene synthase promoters. BMC Genomics 2014; 15: 402

[51] Shang Y, Ma Y, Zhou Y, Zhang H, Duan L, Chen H, Zeng J, Zhou Q, Wang S, Gu W, Liu M, Ren J, Gu X, Zhang S, Wang Y, Yasukawa K, Bouwmeester HJ, Qi X, Zhang Z, Lucas WJ, Huang S. Biosynthesis, regulation, and domestication of bitterness in cucumber. Science 2014; 346: 1084-1088

[52] Van Moerkercke A, Steensma P, Schweizer F, Pollier ], Gariboldi I, Payne R, Vanden Bossche R, Miettinen K, Espoz J, Purnama PC, Kellner F, Seppänen-Laakso T, O'Connor SE, Rischer H, Memelink J, Goossens A. The bHLH transcription factor BIS1 controls the iridoid branch of the monoterpenoid indole alkaloid pathway in Catharanthus roseus. Proc Natl Acad Sci U S A 2015; 112: 8130-8135

[53] Mertens J, Pollier J, Vanden Bossche R, Lopez-Vidriero I, Franco-Zorrilla JM, Goossens A. The bHLH transcription factors TSAR1 and TSAR2 regulate triterpene saponin biosynthesis in Medicago truncatula. Plant Physiol 2016; 170: 194-210

[54] Mertens J, Van Moerkercke A, Vanden Bossche R, Pollier J, Goossens A. Clade IV a basic helix-loop-helix transcription factors form part of a conserved jasmonate signaling circuit for the regulation of bioactive plant terpenoid biosynthesis. Plant Cell Physiol 2016; 57: 2564-2575

[55] Jarvis DE, Ho YS, Lightfoot DJ, Schmöckel SM, Li B, Borm TJA, Ohyanagi $H$, Mineta K, Michell CT, Saber N, Kharbatia NM, Rupper RR, Sharp AR, Dally N, Boughton BA, Woo YH, Gao G, Schijlen EG, Guo X, Momin AA, Negrão S, Al-Babili S, Gehring C, Roessner U, Jung C, Murphy K, Arold ST, Gojobori T, van der Linden CG, van Loo EN, Jellen EN, Maughan PJ, Tester M. The genome of Chenopodium quinoa. Nature 2017; 542: 307-312

[56] Tamura K, Yoshida K, Hiraoka Y, Sakaguchi D, Chikugo A, Mochida K, Kojoma M, Mitsuda N, Saito K, Muranaka T, Seki H. The basic helixloop-helix transcription factor GubHLH3 positively regulates soyasaponin biosynthetic genes in Glycyrrhiza uralensis. Plant Cell Physiol 2018; 59: 783-796

[57] Hemmerlin A, Harwood JL, Bach T]. A raison d'être for two distinct pathways in the early steps of plant isoprenoid biosynthesis? Prog Lipid Res 2012; 51: 95-148
[58] Rodríguez-Concepción M. Early steps in isoprenoid biosynthesis: multilevel regulation of the supply of common precursors in plant cells. Phytochem Rev 2006; 5: 1-15

[59] Friesen JA, Rodwell VW. The 3-hydroxy-3-methylglutaryl coenzyme-A (HMG-CoA) reductases. Genome Biol 2004; 5: 248

[60] Kumari S, Priya P, Misra G, Yadav G. Structural and biochemical perspectives in plant isoprenoid biosynthesis. Phytochem Rev 2013; 12: 255 291

[61] Campos N, Boronat A. Targeting and topology in the membrane of plant 3-hydroxy-3-methylglutaryl coenzyme A reductase. Plant Cell 1995; 7: 2163-2174

[62] Lum PY, Edwards S, Wright R. Molecular, functional and evolutionary characterization of the gene encoding HMG-CoA reductase in the fission yeast, Schizosaccharomyces pombe. Yeast 1996; 12: 1107-1124

[63] Hampton R, Dimster-Denk D, Rine J. The biology of HMG-CoA reductase: the pros of contra-regulation. Trends Biochem Sci 1996; 21: 140-145

[64] Brown MS, Dana SE, Dietschy JM, Siperstein MD. 3-Hydroxy-3-methylglutaryl coenzyme A reductase. Solubilization and purification of a cold-sensitive microsomal enzyme. J Biol Chem 1973; 248: 4731-4738

[65] Li W, Liu W, Wei H, He Q, Chen J, Zhang B, Zhu S. Species-specific expansion and molecular evolution of the 3-hydroxy-3-methylglutaryl coenzyme A reductase (HMGR) gene family in plants. PLoS One 2014; 9: e94172

[66] Liu W, Zhang Z, Li W, Zhu W, Ren Z, Wang Z, Li L, Jia L, Zhu S, Ma Z. Genome-wide identification and comparative analysis of the 3-hydroxy3-methylglutaryl coenzyme A reductase (HMGR) gene family in Gossypium. Molecules 2018; 23: 193

[67] Basson ME, Thorsness M, Finer-Moore J, Stroud RM, Rine J. Structural and functional conservation between yeast and human 3-hydroxy-3-methylglutaryl coenzyme A reductases, the rate-limiting enzyme of sterol biosynthesis. Mol Cell Biol 1988; 8: 3797-3808

[68] Istvan ES, Palnitkar M, Buchanan SK, Deisenhofer ]. Crystal structure of the catalytic portion of human HMG-CoA reductase: insights into regulation of activity and catalysis. EMBO | 2000; 19: 819-830

[69] Profant DA, Roberts C], Koning AJ, Wright RL. The role of the 3-hydroxy 3-methylglutaryl coenzyme A reductase cytosolic domain in karmellae biogenesis. Mol Biol Cell 1999; 10: 3409-3423

[70] Hampton RY, Gardner RG, Rine J. Role of 265 proteasome and HRD genes in the degradation of 3-hydroxy-3-methylglutaryl-CoA reductase, an integral endoplasmic reticulum membrane protein. Mol Biol Cell 1996; 7: 2029-2044

[71] Hampton RY, Rine J. Regulated degradation of HMG-CoA reductase, an integral membrane protein of the endoplasmic reticulum, in yeast. J Cell Biol 1994; 125: 299-312

[72] Vollack KU, Dittrich B, Ferrer A, Boronat A, Bach T]. Two radish genes for 3-hydroxy-3-methylglutaryl-coa reductase isozymes complement mevalonate auxotrophy in a yeast mutant and yield membrane-bound active enzyme. J Plant Physiol 1994; 143: 479-487

[73] Burg JS, Espenshade PJ. Regulation of HMG-CoA reductase in mammals and yeast. Prog Lipid Res 2011; 50: 403-410

[74] Gardner R, Cronin S, Leder B, Rine ], Hampton R. Sequence determinants for regulated degradation of yeast 3-hydroxy-3-methylglutaryl-CoA reductase, an integral endoplasmic reticulum membrane protein. Mol Biol Cell 1998; 9: 2611-2626

[75] Kumagai H, Chun KT, Simoni RD. Molecular dissection of the role of the membrane domain in the regulated degradation of 3-hydroxy-3-methylglutaryl coenzyme A reductase. J Biol Chem 1995; 270: 19107-19113

[76] Sever N, Yang T, Brown MS, Goldstein JL, DeBose-Boyd RA. Accelerated degradation of HMG CoA reductase mediated by binding of Insig- 1 to its sterol-sensing domain. Mol Cell 2003; 11: 25-33

[77] Theesfeld CL, Pourmand D, Davis T, Garza RM, Hampton RY. The sterolsensing domain (SSD) directly mediates signal-regulated endoplasmic reticulum-associated degradation (ERAD) of 3-hydroxy-3-methylglutaryl 
(HMG)-CoA reductase isozyme HMG2. J Biol Chem 2011; 286: 2629826307

[78] DeBose-Boyd RA. Feedback regulation of cholesterol synthesis: sterolaccelerated ubiquitination and degradation of HMG CoA reductase. Cell Res 2008; 18: 609-621

[79] Tsai YC, Leichner GS, Pearce MMP, Wilson GL, Wojcikiewicz RJH, Roitelman J, Weissman AM. Differential regulation of HMG-CoA reductase and Insig- 1 by enzymes of the ubiquitin-proteasome system. Mol Biol Cell 2012; 23: 4484-4494

[80] Lee JN, Song B, DeBose-Boyd RA, Ye J. Sterol-regulated degradation of Insig-1 mediated by the membrane-bound ubiquitin ligase gp78. J Biol Chem 2006; 281: 39308-39315

[81] Song BL, Sever N, DeBose-Boyd RA. Gp78, a membrane-anchored ubiquitin ligase, associates with Insig-1 and couples sterol-regulated ubiquitination to degradation of HMG CoA reductase. Mol Cell 2005; 19: $829-840$

[82] Sever N, Song BL, Yabe D, Goldstein JL, Brown MS, DeBose-Boyd RA. Insig-dependent ubiquitination and degradation of mammalian 3-hydroxy-3-methylglutaryl-CoA reductase stimulated by sterols and geranylgeraniol. J Biol Chem 2003; 278: 52479-52490

[83] Hampton RY, Bhakta H. Ubiquitin-mediated regulation of 3-hydroxy-3methylglutaryl-CoA reductase. Proc Natl Acad Sci U S A 1997; 94 : $12944-12948$

[84] Garza RM, Tran PN, Hampton RY. Geranylgeranyl pyrophosphate is a potent regulator of HRD-dependent 3-hydroxy-3-methylglutaryl-CoA reductase degradation in yeast. J Biol Chem 2009; 284: 35368-35380

[85] Gardner RG, Shan H, Matsuda SPT, Hampton RY. An oxysterol-derived positive signal for 3-hydroxy-3-methylglutaryl-CoA reductase degradation in yeast. J Biol Chem 2001; 276: 8681-8694

[86] Foresti O, Ruggiano A, Hannibal-Bach HK, Ejsing CS, Carvalho P. Sterol homeostasis requires regulated degradation of squalene monooxygenase by the ubiquitin ligase Doa10/Teb4. Elife 2013; 2013: e00953

[87] Schumacher MM, Jun DJ, Jo Y, Seemann J, DeBose-Boyd RA. Geranylgeranyl-regulated transport of the prenyltransferase UBIAD1 between membranes of the ER and Golgi. J Lipid Res 2016; 57: 1286-1299

[88] Schumacher MM, Jun DJ, Johnson BM, DeBose-Boyd RA. UbiA prenyltransferase domain-containing protein-1 modulates HMG-CoA reductase degradation to coordinate synthesis of sterol and nonsterol isoprenoids. J Biol Chem 2018; 293: 312-323

[89] Hemmerlin A, Bach TJ. Effects of mevinolin on cell cycle progression and viability of tobacco BY-2 cells. Plant J 1998; 14: 65-74

[90] Kondo K, Uritani I, Oba K. Induction mechanism of 3-hydroxy-3-methylglutaryl-CoA reductase in potato tuber and sweet potato root tissues. Biosci Biotechnol Biochem 2003; 67: 1007-1017

[91] Korth KL, Jaggard DAW, Dixon RA. Developmental and light-regulated post-translational control of 3-hydroxy-3-methylglutaryl-CoA reductase levels in potato. Plant J 2000; 23: 507-516

[92] Rodríguez-Concepción M, Forés O, Martínez-García JF, González V, Phillips MA, Ferrer A, Boronat A. Distinct light-mediated pathways regulate the biosynthesis and exchange of isoprenoid precursors during Arabidopsis seedling development. Plant Cell 2004; 16: 144-156

[93] Russell DW, Davidson H. Regulation of cytosolic HMG-CoA reductase activity in pea seedlings: contrasting responses to different hormones, and hormone-product interaction, suggest hormonal modulation of activity. Biochem Biophys Res Commun 1982; 104: 1537-1543

[94] Dale S, Arró M, Becerra B, Morrice NG, Boronat A, Hardie DG, Ferrer A. Bacterial expression of the catalytic domain of 3-hydroxy-3-methylglutaryl-CoA reductase (isoform HMGR1) from Arabidopsis thaliana, and its inactivation by phosphorylation at Ser577 by Brassica oleracea 3-hydroxy-3-methylglutaryl-CoA reductase kinase. Eur J Biochem 1995; 233 : $506-513$
[95] Douglas P, Pigaglio E, Ferrer A, Halford NG, Mackintosh C. Three spinach leaf nitrate reductase-3-hydroxy-3-methylglutaryl-CoA reductase kinases that are regulated by reversible phosphorylation and/or $\mathrm{Ca}^{2+}$ ions. Biochem ] 1997; 325: 101-109

[96] Denbow C], Lång S, Cramer CL. The N-terminal domain of tomato 3 hydroxy-3-methylglutaryl-CoA reductases. Sequence, microsomal targeting, and glycosylation. J Biol Chem 1996; 271: 9710-9715

[97] Durek P, Schmidt R, Heazlewood JL, Jones A, MacLean D, Nagel A, Kersten B, Schulze WX. PhosPhAt: the Arabidopsis thaliana phosphorylation site database. An update. Nucleic Acids Res 2010; 38: D828D834

[98] Gnad F, Gunawardena J, Mann M. PHOSIDA 2011: the posttranslational modification database. Nucleic Acids Res 2011; 39: D253-D260

[99] Grimsrud PA, den Os D, Wenger CD, Swaney DL, Schwartz D, Sussman MR, Ane JM, Coon JJ. Large-scale phosphoprotein analysis in Medicago truncatula roots provides insight into in vivo kinase activity in legumes. Plant Physiol 2010; 152: 19-28

[100] Heazlewood JL, Durek P, Hummel ], Selbig J, Weckwerth W, Walther D, Schulze WX. PhosPhAt: a database of phosphorylation sites in Arabidopsis thaliana and a plant-specific phosphorylation site predictor. Nucleic Acids Res 2008; 36: D1015-D1021

[101] Stermer BA, Bianchini GM, Korth KL. Regulation of HMG-CoA reductase activity in plants. J Lipid Res 1994; 35: 1133-1140

[102] Pollier J, Moses T, González-Guzmán M, De Geyter N, Lippens S, Vanden Bossche R, Marhavý P, Kremer A, Morreel K, Guérin C], Tava A, Oleszek W, Thevelein JM, Campos N, Goormachtig S, Goossens A. The protein quality control system manages plant defence compound synthesis. Nature 2013; 504: 148-152

[103] Doblas VG, Amorim-Silva V, Posé D, Rosado A, Esteban A, Arró M, Azevedo H, Bombarely A, Borsani O, Valpuesta V, Ferrer A, Tavares RM, Botella MA. The SUD1 gene encodes a putative E3 ubiquitin ligase and is a positive regulator of 3-hydroxy-3-methylglutaryl coenzyme A reductase activity in Arabidopsis. Plant Cell 2013; 25: 728-743

[104] Kim SM, Wang Y, Nabavi N, Liu Y, Correia MA. Hepatic cytochromes P450: structural degrons and barcodes, posttranslational modifications and cellular adapters in the ERAD-endgame. Drug Metab Rev 2016; 48: 405-433

[105] Schnepf E. Gland Cells. In: Robards AW, ed. Dynamic Aspects of Plant Ultrastructure. London: McGraw Hill; 1974: 331-357

[106] Fawcett DW. The Cell. Philadelphia: Saunders; 1981: 303-309

[107] Chin DJ, Luskey KL, Anderson RGW, Faust JR, Goldstein JL, Brown MS. Appearance of crystalloid endoplasmic reticulum in compactin-resistant Chinese hamster cells with a 500-fold increase in 3-hydroxy-3methylglutaryl-coenzyme A reductase. Proc Natl Acad Sci U S A 1982; 79: 1185-1189

[108] Anderson RGW, Orci L, Brown MS, Garcia-Segura LM, Goldstein JL. Ultrastructural analysis of crystalloid endoplasmic reticulum in UT-1 cells and its disappearance in response to cholesterol. J Cell Sci 1983; 63: $1-20$

[109] Orci L, Brown MS, Goldstein JL, Garcia-Segura LM, Anderson RGW. Increase in membrane cholesterol: a possible trigger for degradation of HMG CoA reductase and crystalloid endoplasmic reticulum in UT-1 cells. Cell 1984; 36: 835-845

[110] Pathak RK, Luskey KL, Anderson RGW. Biogenesis of the crystalloid endoplasmic reticulum in UT-1 cells: evidence that newly formed endoplasmic reticulum emerges from the nuclear envelope. J Cell Biol 1986; 102: 2158-2168

[111] Lum PY, Wright R. Degradation of HMG-CoA reductase-induced membranes in the fission yeast, Schizosaccharomyces pombe. J Cell Biol 1995; 131: 81-94

[112] Parrish ML, Sengstag C, Rine JD, Wright RL. Identification of the sequences in $\mathrm{HMG}-\mathrm{CoA}$ reductase required for karmellae assembly. Mol Biol Cell 1995; 6: 1535-1547 
[113] Snapp EL, Hegde RS, Francolini M, Lombardo F, Colombo S, Pedrazzini E, Borgese N, Lippincott-Schwartz J. Formation of stacked ER cisternae by low affinity protein interactions. J Cell Biol 2003; 163: 257-269

[114] Ferrero S, Grados-Torrez RE, Leivar P, Antolín-Llovera M, López-Iglesias C, Cortadellas N, Ferrer JC, Campos N. Proliferation and morphogenesis of the endoplasmic reticulum driven by the membrane domain of 3-hydroxy-3-methylglutaryl coenzyme A reductase in plant cells. Plant Physiol 2015; 168: 899-914

[115] Walter P, Johnson AE. Signal sequence recognition and protein targeting to the endoplasmic reticulum membrane. Annu Rev Cell Biol 1994; 10: $87-119$

[116] Rapoport TA. Protein translocation across the eukaryotic endoplasmic reticulum and bacterial plasma membranes. Nature 2007; 450: 663669

[117] Lütcke H. Signal recognition particle (SRP), a ubiquitous initiator of protein translocation. Eur J Biochem 1995; 228: 531-550

[118] Schubert U, Antón LC, Gibbs J, Norbury CC, Yewdell JW, Bennink JR. Rapid degradation of a large fraction of newly synthesized proteins by proteasomes. Nature 2000; 404: 770-774

[119] Olzmann JA, Kopito RR, Christianson JC. The mammalian endoplasmic reticulum-associated degradation system. Cold Spring Harb Perspect Biol 2013; 5: a013185

[120] Liu JX, Howell SH. Managing the protein folding demands in the endoplasmic reticulum of plants. New Phytol 2016; 211: 418-428

[121] Caarls L, Pieterse CMJ, Van Wees SCM. How salicylic acid takes transcriptional control over jasmonic acid signaling. Front Plant Sci 2015; 6: 170

[122] Smith JL, De Moraes CM, Mescher MC. Jasmonate- and salicylate-mediated plant defense responses to insect herbivores, pathogens and parasitic plants. Pest Manag Sci 2009; 65: 497-503

[123] Farmer EE, Ryan CA. Octadecanoid precursors of jasmonic acid activate the synthesis of wound-inducible proteinase-inhibitors. Plant Cell 1992; 4: 129-134

[124] Liu Y, Ahn JE, Datta S, Salzman RA, Moon J, Huyghues-Despointes B, Pittendrigh B, Murdock LL, Koiwa H, Zhu-Salzman K. Arabidopsis vegetative storage protein is an anti-insect acid phosphatase. Plant Physiol 2005; 139: 1545-1556

[125] Verma V, Ravindran P, Kumar PP. Plant hormone-mediated regulation of stress responses. BMC Plant Biol 2016; 16: 86

[126] Robert-Seilaniantz A, Grant M, Jones JDG. Hormone crosstalk in plant disease and defense: more than just jasmonate-salicylate antagonism. Annu Rev Phytopathol 2011; 49: 317-343

[127] Bari R, Jones JDG. Role of plant hormones in plant defence responses. Plant Mol Biol 2009; 69: 473-488

[128] Moreno AA, Mukhtar MS, Blanco F, Boatwright JL, Moreno I, Jordan MR, Chen Y, Brandizzi F, Dong X, Orellana A, Pajerowska-Mukhtar KM. IRE1/ bZIP60-mediated unfolded protein response plays distinct roles in plant immunity and abiotic stress responses. PLoS One 2012; 7: e31944

[129] Tateda C, Ozaki R, Onodera Y, Takahashi Y, Yamaguchi K, Berberich T, Koizumi N, Kusano T. NtbZIP60, an endoplasmic reticulum-localized transcription factor, plays a role in the defense response against bacterial pathogens in Nicotiana tabacum. J Plant Res 2008; 121: 603-611

[130] Wang D, Weaver ND, Kesarwani M, Dong X. Induction of protein secretory pathway is required for systemic acquired resistance. Science 2005; 308: 1036-1040

[131] Jia XY, Xu CY, jing RL, Li RZ, Mao XG, Wang JP, Chang XP. Molecular cloning and characterization of wheat calreticulin (CRT) gene involved in drought-stressed responses. J Exp Bot 2008; 59: 739-751

[132] Valente MAS, Faria JA, Soares-Ramos JRL, Reis PAB, Pinheiro GL, Piovesan ND, Morais AT, Menezes CC, Cano MAO, Fietto LG, Loureiro $\mathrm{ME}$, Aragão FJL, Fontes EPB. The ER luminal binding protein (BiP) mediates an increase in drought tolerance in soybean and delays droughtinduced leaf senescence in soybean and tobacco. J Exp Bot 2009; 60: $533-546$

[133] Zhang H, Ohyama K, Boudet J, Chen Z, Yang J, Zhang M, Muranaka T, Maurel C, Zhu JK, Gong Z. Dolichol biosynthesis and its effects on the unfolded protein response and abiotic stress resistance in Arabidopsis. Plant Cell 2008; 20: 1879-1898

[134] Liu JX, Srivastava R, Che P, Howell SH. An endoplasmic reticulum stress response in Arabidopsis is mediated by proteolytic processing and nuclear relocation of a membrane-associated transcription factor, bZIP28. Plant Cell 2007; 19: 4111-4119

[135] Gao HB, Brandizzi F, Benning C, Larkin RM. A membrane-tethered transcription factor defines a branch of the heat stress response in Arabidopsis thaliana. Proc Natl Acad Sci U S A 2008; 105: 16398-16403

[136] Liu JX, Srivastava R, Che P, Howell SH. Salt stress responses in Arabidopsis utilize a signal transduction pathway related to endoplasmic reticulum stress signaling. Plant J 2007; 51: 897-909

[137] Che P, Bussell JD, Zhou W, Estavillo GM, Pogson BJ, Smith SM. Signaling from the endoplasmic reticulum activates brassinosteroid signaling and promotes acclimation to stress in Arabidopsis. Sci Signal 2010; 3: ra69

[138] Zhou SF, Sun L, Valdés AE, Engström P, Song ZT, Lu SJ, Liu JX. Membrane-associated transcription factor peptidase, Site-2 protease, antagonizes ABA signaling in Arabidopsis. New Phytol 2015; 208: 188197

[139] Chen Y, Brandizzi F. AtIRE1A/AtIRE1B and AGB1 independently contro two essential unfolded protein response pathways in Arabidopsis. Plant J 2012; 69: 266-277

[140] Srivastava R, Chen Y, Deng Y, Brandizzi F, Howell SH. Elements proximal to and within the transmembrane domain mediate the organelleto-organelle movement of bZIP28 under ER stress conditions. Plant J 2012; 70: 1033-1042 